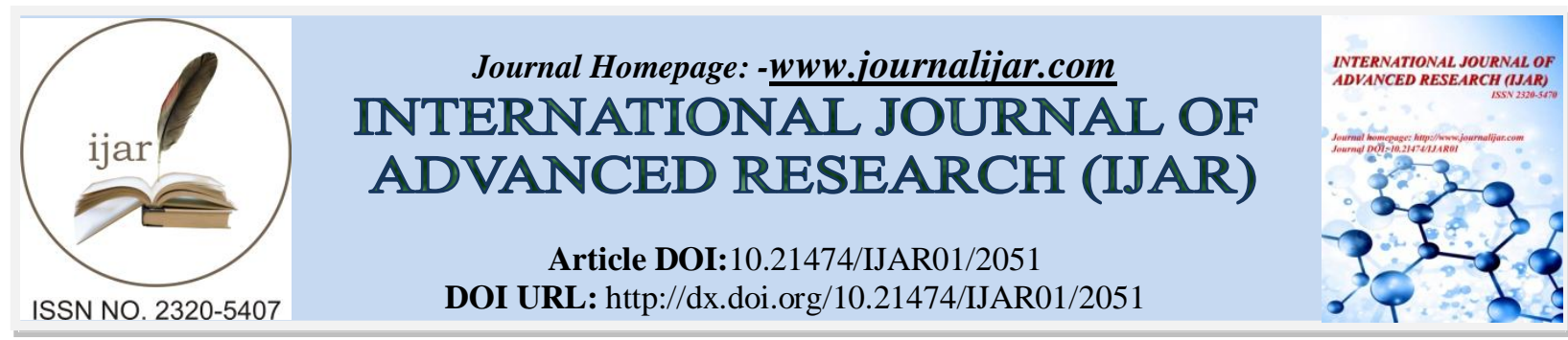

RESEARCH ARTICLE

\title{
EFFECTS OF AQUEOUS EXTRACT OF PERSEA AMERICANA ON THE HISTOLOGY OF THE KIDNEY OF ALBINO RATS.
}

\author{
D. S. Amaza ${ }^{1 *}$, J. V. Zirahei ${ }^{2}$, A. D. T. Goji ${ }^{2}$, Helga B. Ishaya ${ }^{2}$, H. Mari ${ }^{3}$ and N. Victoria ${ }^{2}$. \\ 1. Department of Human Anatomy, Faculty of Medicine, Kaduna State University, Kaduna State, Nigeria. \\ 2. Department of Human Anatomy, College of Medical Sciences, University of Maiduguri, Borno State, Nigeria. \\ 3. Department of Biological Sciences, Faculty of Science, University of Maiduguri, Borno State, Nigeria.
}

\section{Manuscript Info}

\section{Manuscript History}

Received: 20 September 2016

Final Accepted: 22 October 2016

Published: November 2016

Key words:-

Persea americana; aqueous leaves extract; kidney; rats; histological changes

\section{Abstract}

This study investigated the effects of aqueous leaf extract of Persea americana (avocado) on the histology of the kidney of albino rats apparently healthy. A total of 25 albino rats weighing 160-200g were used for the study. The rats were randomly divided into five groups of five rats each. They were treated with aqueous extract of Persea Americana for a period of 28 days. Group A received normal saline (control). While groups B, C and D were treated orally with the extract daily at the doses of 250,500 and $750 \mathrm{mg} / \mathrm{kg}$ weight respectively for 28 days. At the end of the experiment, kidney sections were processed using light microscopic techniques and stained with Hematoxylin and Eosin. Histological examinations were supplemented by biochemical assay analysis. The kidney of rats treated with $250 \mathrm{mg} / \mathrm{kg}$ of extract showed glomerular degeneration and tubular necrosis in the cortex. The kidney of rats treated with 500 $\mathrm{mg} / \mathrm{kg}$ of extract revealed mild hydrophobic change in the lumen of the tubules and tubular ballooning. The kidney treated with $750 \mathrm{mg} / \mathrm{kg}$ of extract resulted in severe hydrophobic changes within the lumen, tubular ballooning and mild inflammatory cells. The finding of the study concluded that aqueous leaf extract of Persea americana have effects on the histology of the kidney. Administration of Perseaamericana causes dose- dependent degeneration of glomeruli and tubular necrosis in the cortex, hydrophobic change in the lumen of the tubules and tubular ballooning and mild inflammatory cells. Further toxicity studies (sub-acute and chronic) of the crude extract and organic solvent portions needs to be carried out using different animal models in order to evaluate the long-term effects of the extract.

Copy Right, IJAR, 2016. All rights reserved.

\section{Introduction:-}

Nature has provided human beings through the ages with medicinal plants as the premier form of healthcare. Medicinal plants have given hope to man in the quest for healing old and emerging diseases that have defied many orthodox drugs. Medicinal plants gave hope to man in the quest for healing old and emerging diseases that have defied many orthodox drugs (WHO, 2009). Medicinal plants are considered safer and better than synthetic drugs, as

Corresponding Author:-D. S. Amaza.

Address:-Department of Human Anatomy, Faculty of Medicine, Kaduna State University, Kaduna State, Nigeria. 
ingredients in plants such as carbohydrates, fats, protein, vitamins and minerals are also of body composition (Kilham 1999).

The name"avocado" also refers to the fruit of the Kupa shell that contains a pill (hard seed which may be egg shaped or spherical). High Persea Americana (avocado) extract intake has been shown to have effect on serum cholesterol levels. Specifically, after a seven day diet rich in Persea americana leaf extract. Nigerian herbalists use the aqueous seed extract for the management of hypertension [1]. The aqueous leaf extract has also been demonstrated to possess analgesic and anti-inflammatory activities (Adeyemi et al., 2002). Other medicinal properties of Persea americana are wound healing (Nayak et al., 2008) and hepatoprotection (Kawagishi et al., 2001).

Avocado toxicity was reported as early as 1942 in California [7].The leaves, bark, seeds and skin of the fruit are toxic and leaves remain toxic after dried. In mammals that have been experimentally fed dried leaves suffered cell death of the mammary glands which are commonly observed clinical finding in livestock, including goats and cattle, known to have ingested avocado plant parts [8]. Avocado leaves are very toxic to rabbits as it produced severe degenerative cellular changes in vital organs such as liver, kidneys and heart causing high mortality [9]. The aim of the study therefore was to investigate the effect of aqueous leaf extract of avocado on the histology of the Kidney tissue.

\section{Materials and methods:- Extract Preparation:-}

The leaf of mature Persea americana was collected from Sardauna Local Government Area of Taraba State and was identified at the Department of Botany, Faculty of Sciences, University of Maiduguri. The leaves were thoroughly washed and air dried in the laboratory for a period of ten days. The dried leaves were pounded to a fine powder using pestle and mortar and then stored in a dry cylinder. The powdered leaf was extracted with water using soxhlet extraction method for six hours. The solution obtained was concentrated in the oven at a temperature of $45^{\circ} \mathrm{C}$ and further dried into a fine powder at a temperature of $50^{\circ} \mathrm{C}$.

\section{Experimental Animals:-}

Twenty- five (25) apparently healthy male albino rats weighing 160-200g were used for the study. The rats were obtained from the animal house of the Department of Anatomy, University of Human Jos and allowed to acclimatize in the animal house of the Department of Human Anatomy, College of Medical Sciences, University of Maiduguri, for 2 weeks prior to experimentation. They were housed in standard well aerated laboratory cages, where bedding was replaced every two days, at a room temperature of about $27^{\circ} \mathrm{C}$ and 12 hour light/dark cycle. The rats were fed on standard rat chow and allowed free access to drinking water ad libitum.

\section{Experimental Design:-}

The rats were randomly divided into five groups of five rats each $(n=5)$. They were treated with aqueous extract of Persea americana for a period of 28 days. Group A received normal saline orally (control), while groups B, C and D were treated orally by the use of the orogastric tube sterilized with K-Y gel, before use with the extract daily at the doses of 250,500 and $750 \mathrm{mg} / \mathrm{kg}$ weight respectively for 28 days. At the $29^{\text {th }}$ day, each rat was anaesthetized with cotton wool soaked in chloroform, and then supported on dissecting bed in dorsal decubitus position; the limbs were abducted and held with pins to keep the muscles in position. Scalpel blade, sharp scissors were then used to cut and open up the abdominal region. Using forceps, the kidneys were held and removed and transferred immediately into already prepared $10 \%$ formalin in specimen bottles.

\section{Biochemical Analysis:-}

Blood sample were obtained by cardiac puncture $(4 \mathrm{ml})$ from each rat in the study group after light anaesthesia into plain sample bottles. The samples were allowed to coagulated and then centrifuged at $3000 \mathrm{~g}$ for $10 \mathrm{~min}$ at $4^{\circ} \mathrm{c}$ to obtain serum. The serum samples were then used for biochemical analysis.

\section{Histological Tissue Processing:-}

The fixed Kidney tissues were sectioned (5-micron thickness) and processed using the routine light microscopic techniques and stained with Hematoxylin and Eosin. Histological examinations were supplemented by biochemical assay analysis. Experimental protocols and procedures used in this study were approved by the Ethical Committee of the University of Maiduguri, Borno State, Nigeria. They also conform to the guidelines in the 'Principles of Laboratory Animal Care' [10]. 


\section{Statistical Analysis:-}

Results obtained from the study were expressed as mean value \pm standard error of mean (SEM). All analysis was carried out using statistical package Instant, Version 3, Graphpad Software Inc. [11]. A statistical significance was taken at probability level of less than $5 \%(\mathrm{P}<0.05)$.

\section{Results:-}

\section{Gross Anatomical Observation:-}

Following administration of the aqueous extract of Persea americana orally to the rats, it was obtained resulted to dehydration, rough hair coat and anorexia (fail to eat for some hours) and the faecal matter of the experimental groups became slightly watery two (2) days after commencement of the extract administration. However, these faecal matters and gross changes returned to normalcy after the fourth day. There were significant increases in weight at the low dose $(250 \mathrm{mg} / \mathrm{kg})$ from days 14 through 28 with respect to the control group. The result of the serum blood electrolytes (Table 2), shows that there are no significant changes in serum urea, creatinine, serum sodium ions $(\mathrm{Na}+)$, potassium ions $(\mathrm{K}+)$, serum chloride ions and serum electrolyte bicarbonate ions (HCO3-) of the rats treated with respect to the control $(\mathrm{P}>0.05)$ as in Table 2 .

The Kidney tissue of rats treated with $250 \mathrm{mg} / \mathrm{kg}$ of extract show glomerular degeneration and tubular necrosis in the cortex (Fig.3). Kidney section of rats treated with 500mgkg of extract shows mild hydrophobic change in the lumen of the tubules and tubular ballooning (Fig.4). While the extract of $750 \mathrm{mg} / \mathrm{kg}$ of results in severe hydrophobic change within the lumen, tubular ballooning and mild inflammatory cells (Figs.5 \& 6).

Table 1:-Effect of the aqueous extract on the weight of the albino rats.

\begin{tabular}{|l|l|l|l|l|}
\hline Dose (mg/kg) & Day 7 & Day 14 & Day 21 & Day 28 \\
\hline Saline & $211.60 \pm 28.89$ & $211.60 \pm 28.89$ & $211.60 \pm 28.89$ & $211.60 \pm 28.89$ \\
\hline $\mathbf{2 5 0}$ & $256.80 \pm 19.56$ & $282.78 \pm 22.78^{*}$ & $280.53 \pm 26.85^{*}$ & $305.63 \pm 27.62^{* *}$ \\
\hline $\mathbf{5 0 0}$ & $220.83 \pm 31.86$ & $228.53 \pm 23.30$ & $235.23 \pm 24.25$ & $244.83 \pm 8.62$ \\
\hline $\mathbf{7 5 0}$ & $197.66 \pm 20.54$ & $211.28 \pm 33.05$ & $213.93 \pm 40.84$ & $227.63 \pm 40.03$ \\
\hline
\end{tabular}

$* \mathrm{P}<0.05, * * \mathrm{P}<0.01$ Significant increase compared to control.

Table 2:-Effect of aqueous extract of Persea americana on serum electrolyte and organ weight in Albino rats.

\begin{tabular}{|c|c|c|c|c|c|c|}
\hline \multirow{2}{*}{$\begin{array}{c}\text { Dose } \\
\left(\mathbf{m g k g}^{-1}\right)\end{array}$} & $\begin{array}{c}\text { Trea } \\
(\mathbf{m m o l} / \mathbf{L})\end{array}$ & $\begin{array}{c}\text { Creatinine } \\
(\mathbf{m m o l} / \mathbf{L})\end{array}$ & $\begin{array}{c}\mathbf{N a}^{+} \\
\left(\mathbf{m m o l}_{\mathbf{m}} \mathbf{L}\right)\end{array}$ & $\begin{array}{c}\mathbf{K}^{+} \\
(\mathbf{m m o l} / \mathbf{L})\end{array}$ & $\begin{array}{c}\mathbf{C l}^{-} \\
(\mathbf{m m o l} / \mathbf{L})\end{array}$ & $\begin{array}{c}\mathbf{H C O}_{\mathbf{3}}{ }^{-} \\
(\mathbf{m m o l} / \mathbf{L})\end{array}$ \\
\hline Saline & $7.75 \pm 0.44$ & $126.0 \pm 24.54$ & $164.25 \pm 17.75$ & $7.20 \pm 0.95$ & $120.50 \pm 6.61$ & $22.50 \pm 2.08$ \\
\hline $\mathbf{2 5 0}$ & $7.45 \pm 0.83$ & $126.24 \pm 19.19$ & $164.50 \pm 5.00$ & $6.60 \pm 0.49$ & $122.25 \pm 3.86$ & $22.00 \pm 0.82$ \\
\hline $\mathbf{5 0 0}$ & $7.05 \pm 1.07$ & $116.50 \pm 15.26$ & $174.00 \pm 18.26$ & $7.28 \pm 1.48$ & $122.00 \pm 5.42$ & $22.50 \pm 1.29$ \\
\hline $\mathbf{7 5 0}$ & $6.28 \pm 1.38$ & $107.50 \pm 13.63$ & $190.00 \pm 8.17$ & $8.73 \pm 0.81$ & $114.50 \pm 10.38$ & $21.75 \pm 2.63$ \\
\hline
\end{tabular}




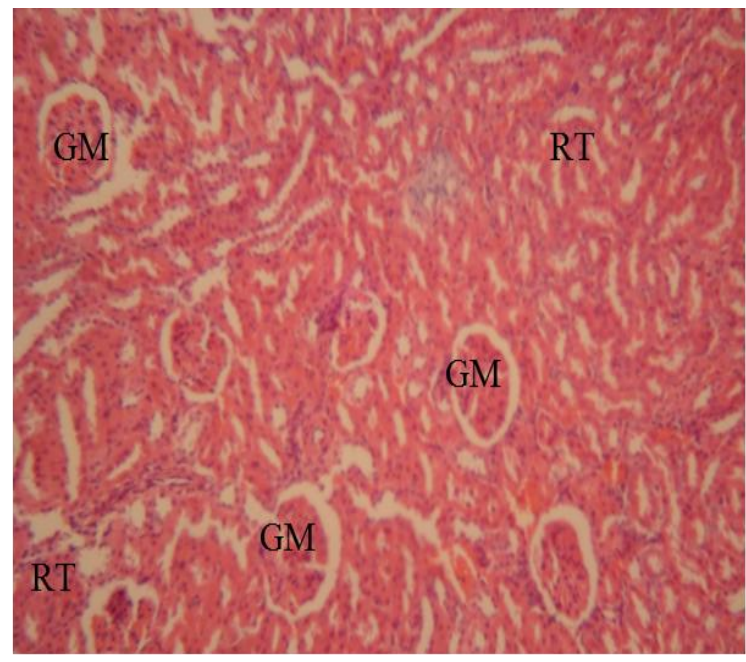

Fig. 1 Photomicrograph of Control rat kidney showing normal glomerulus (GM) and renal tubules (RT) in the cortex H\&E x200.

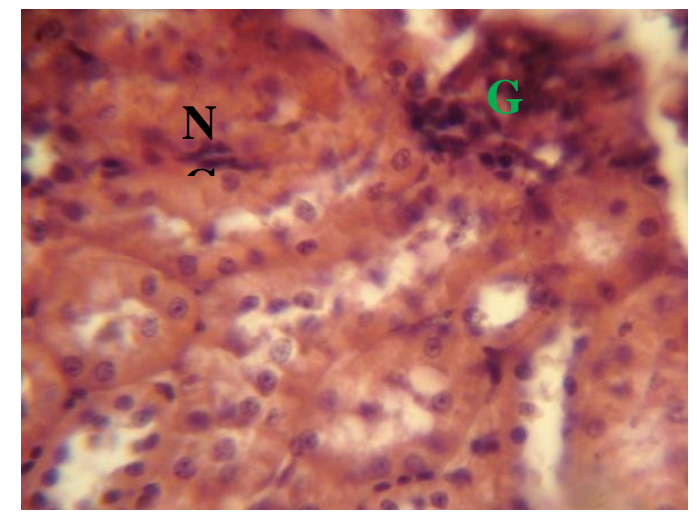

Fig. 3:-Photomicrograph of rat kidney treated with $250 \mathrm{mgkg}$ of extract showing glomerular degeneration (GX) and tubular necrosis NC H\&E x400

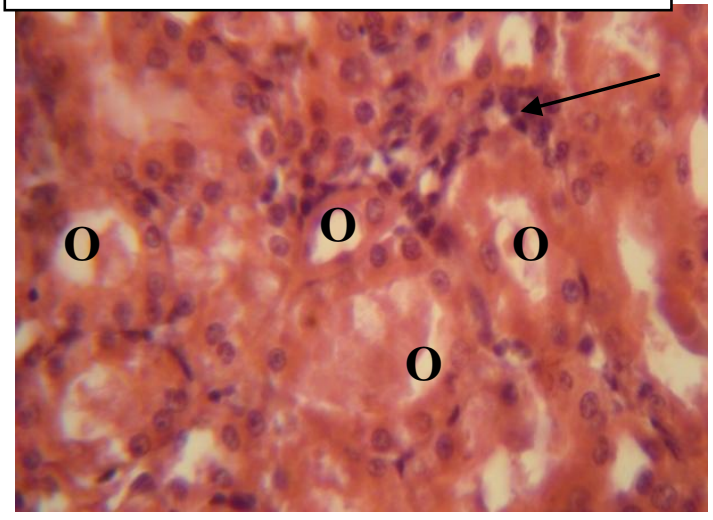

Fig. 5:-Photomicrograph of rat kidney treated with $750 \mathrm{mgkg}$ of extract showing severe hydrophobic change within the lumen $(\mathrm{O})$ and mild inflammatory cells (arrow) H\&E x400.

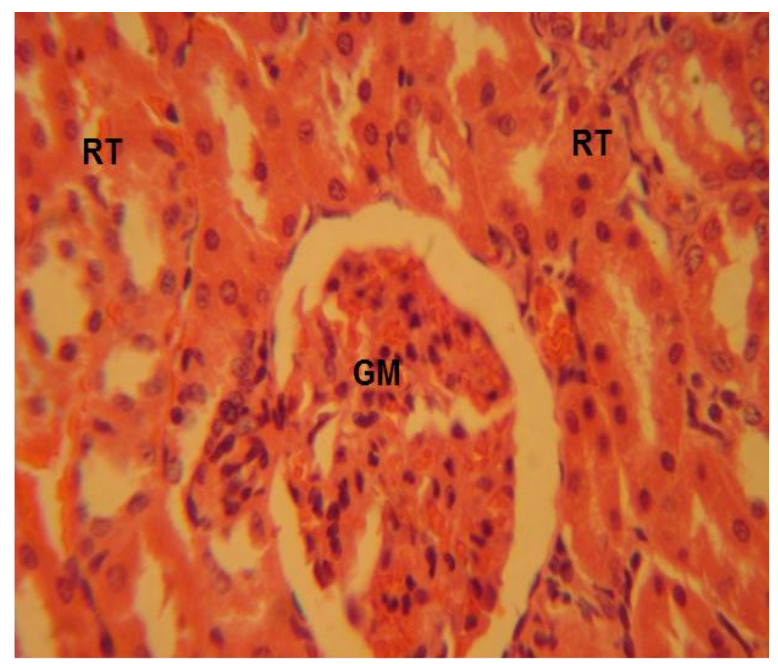

Fig. 2 Photomicrograph of Control rat kidney showing normal glomerulus and renal tubules in the cortex $\mathrm{H} \& \mathrm{E}$ $\mathrm{x} 400$

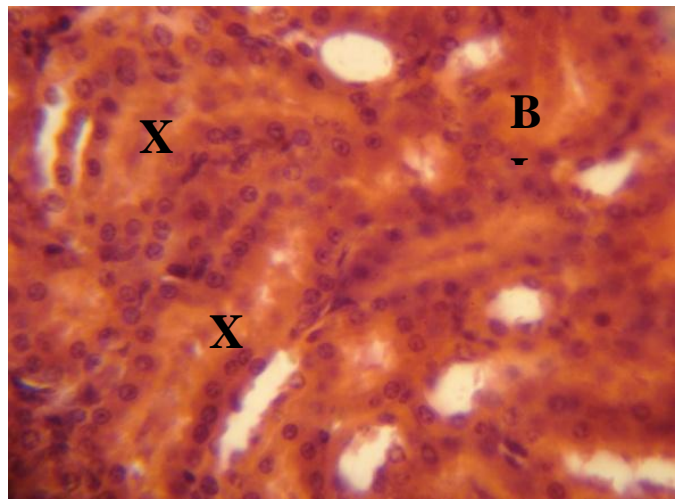

Fig. 4:-Photomicrograph of rat kidney treated with 500mgkg of extract showing mild hydrophobic change in the lumen of the tubules (X) and tubular ballooning (BL) H\&E x400.

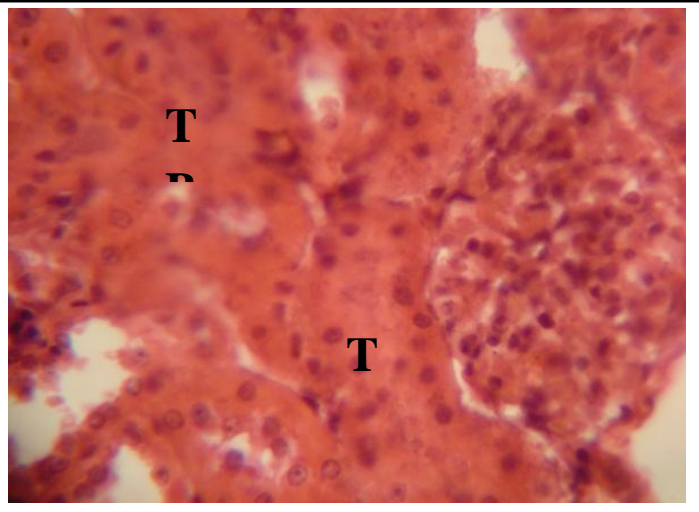

Fig. 6:-Photomicrograph of rat kidney treated with $750 \mathrm{mgkg}$ of extract showing severe tubular ballooning (TB) H\&E x400. (arrow) $\mathrm{H} \& \mathrm{E} \times 400$. 


\section{Discussion:-}

Histological examinations were supplemented by biochemical assay analysis. The kidney of rats treated with $250 \mathrm{mg} / \mathrm{kg}$ of extract showed glomerular degeneration and tubular necrosis in the cortex. The kidney of rats treated with $500 \mathrm{mg} / \mathrm{kg}$ of extract revealed mild hydrophobic change in the lumen of the tubules and tubular ballooning. The kidney treated with $750 \mathrm{mg} / \mathrm{kg}$ of extract resulted in severe hydrophobic changes within the lumen, tubular ballooning and mild inflammatory cells. Administration of Persea Americana causes the dose dependent degeneration of glomeruli and tubular necrosis in the cortex, hydrophobic change in the lumen of the tubules and tubular ballooning and mild inflammatory cells. These observations are comparable to the findings of other workers [12, 13, 14 and 15] who reported scattered non suppurative inflammation in the liver. The histological changes observed were consistent with the biochemical and gross pathological changes reported earlier [16].

Avocado poisoning has been a source of controversy since the fruits are reported to be loaded with nutrients, but there are documented evidences that animals such as cats, dogs, cattle, goats, rabbits, rats, birds, fish, and horses can be severely harmed or even killed when they consume the avocado leaves, bark, skin or pit in large quantity [8 and 17]. Researchers have shown that avocados extracts improved calcium absorption in rats and addition of avocado to salsa significantly improved lycopene, lutein and carotenes absorption in healthy human subjects [18 and 19]. Lopez et al., [20] observed that after a seven-day diet rich in avocados, hypercholesterolemia patients showed a $17 \%, 22 \%$ and $22 \%$ decrease in total serum cholesterol levels, LDL and triglycerides respectively with $11 \%$ in-crease in HDL. However leaves are toxic to rabbits although the toxicity varies with the variety [21, 22]. [9, 22] Observed that avocado leaves are very toxic to rabbits and rats respectively as it produced severe degenerative cellular changes in vital organs such as liver, kidneys and heart causing high mortality. He suggested that rabbits should not be fed with avocado leaves which cause hepatic degeneration throughout the hepatic parenchyma with severe congestion. Hepatic cells were swollen with vacuolation and ruptured at many places. Sinusoidal spaces were dilated and packed with RBCs. Bile ducts revealed mild hyperplasia of mucosal epithelium [9, 22]. It was then recommended that the avocado plant should be planted away from livestock enclosures to avoid accidental poisoning in other species of animals [9 and 22]; these studies are consistent with the present study which also reported similar Liver degenerative changes in albino rats. The finding of this study shows that aqueous leaf extracts of Persea americana have mild to moderate effects on the histology of the kidney.Further toxicity studies (sub-acute and chronic) of the crude extract and organic solvent portions needs to be carried out using different animal models in order to evaluate the long term effects of the extract.

\section{Conclusion:-}

Based on the results and biochemical analysis, it can be concluded that avocado leaves are toxic to albino rats because of the severe degenerative cellular changes observed in the liver tissue. Albino rats should not be fed with avocado leaves. Further toxicity studies (sub-acute and chronic) of the crude extract and organic solvent portions needs to be carried out using different animal models in order to evaluate the long term effects of the extract. A conclusion section must be included and should indicate clearly the advantages, limitations, and possible applications of the paper. Although a conclusion may review the main points of the paper, do not replicate the abstract as the conclusion. A conclusion might elaborate on the importance of the work or suggest applications and extensions. (10)

\section{Acknowledgements:-}

The authors thank Mr. Ibrahim Wuyam, Department of Veterinary Anatomy, University of Maiduguri, Nigeria; for providing laboratory facilities for conducting the experiments.

\section{Competing Interests:-}

Authors Have Declared That No Competing Interests Exist. 


\section{References:-}

1. Ozolua, R.I., Anaka, O.N., Okpo, S.O., Idogun, S.E. (2009). Acute and subacute toxicological assessment of the aqueous seed extract of Persea americana Mill (Lauraceae) in rats. Afr. J Tradit Complement Altern Med., 6(4), 573-578.

2. Ortiz, M.A., Dorantes, A.L., Gallndez, M.J., Cardenas, S.E. (2004). Effect of a novel oil extraction method on avocado (Persea americana) pulp microstructure. Plant Foods Hum Nutr., 59(1), 11-14.

3. Lu Q.Y., Arteaga, J. R, Zhang, Q., Huerta, S., Go, V.L and Heber, D. (2005): Inhibition of prostate cancer cell growth by an avocado extract: role of lipid-soluble bioactive substances. J. Nutr. Biochem. 16: 23-30.

4. Adeyemi, O.O., Okpo, S.O., Ogunti, O.O. (2002). Analgesic and anti-inflammatory effects of the aqueous extract of leaves of Persea americana (Lauraceae). Fitoterapia, 73, 375-380.

5. Nayak, B.S., Raju, S.S., Chalapathi Rao, A.V. (2008). Wound healing activity of Persea americana (avocado) fruit: a preclinical study on rats. J Wound Care, 17(3), 123-126.

6. Kawagishi, H., Fukumoto, Y., Hatakeyama, M., He, P., Arimoto, H., Matsuzawa, T., Arimoto, Y., Suganuma, H., Inakuma, T., Sugiyama, K. (2001). Liver injury suppressing compounds from avocado (Persea americana ). J. Agic Food Chem., 49(5), 2215-21.

7. Appleman D. (1944). Preliminary report on toxicity of avocado leaves. California Society Year Book, p.37.

8. Clipsham, R. (2007) "Avocado Toxicity". http://kgkat.tripod. com/avocado.html. Retrieved 2007-12-29.

9. W. Ramdas Singh, Tridib K. Rajkhowa, KH. Victoria Chanu, M. Ayub Ali, C. Lalmuanthanga, Pritam Mohan M. A. Ayub Shah (2010). Histopathological changes caused by accidental avocado leaves toxicity in rabbits. Int. J. Res. Pharm. Sci. Vol-1, Issue-4, 517-520.

10. NIH. (1985). Guide for the care and use of laboratory animals. DHHS, PHS, NIH Publication. No. 85-23 (1985 Revised).

11. GraphPad Software, InStat-Guide to Choosing and Interpreting Statistical Tests. (2002), GraphPadSoftware, Inc., San Diego Calfornia USA, www.graphpad.com.

12. Craigmill, A.L, Seawright, A.A., Matilla, T., Frost, A.J. (1989). Pathological changes in the mammary gland and bio-chemical changes in milk of the goat following oral dosing with leaf of the avocado (Persea americana). Aus. Vet. J. Vol. 66, pp. 206-211.

13. Sani, Y., Atwell, R.B., Seawright, A.A. (1991). The cardiotoxicity of avocado leaves. Aus Vet J. Vol. 68, pp.150-151.

14. Sani, Y., Seawright, A.A. et al (1994). The toxicity of avocado (Persea Americana) for the heart and lactating mammary gland of the mouse. In Plant Associated Toxins Colegate, S.M., Dorling, P.R., Exeter, UK Eds. CAB International, Short Run Press. Pp.552-556.

15. Grant, R., Basson, P.A., Booker, H.H. (1991). Cardiomyopathy caused by avocado (Persea americana Mill.) leaves. J. South African Vet. Assoc. Vol. 62, pp. 21-22.

16. Ali, M.A., Chanu, K. Victoria, Singh, W. Ramdas, Shah, M.A. Ayub and Devi, L. Geeta (2010). Biochemical and pa-thological changes associated with avocado leaves poisoning in rabbits- a case report. Intl. J. Res. Pharm. Sci. Vol. 1 (Issue3), 225-228.

17. Oelrichs P.B., Ng, J.C., Seawright A.A, Ward A, Schäffeler L, MacLeod J.K (1995). "Isolation and identification of a compound from avocado (Persea americana) leaves which causes necrosis of the acinar epithelium of the lactating mammary gland and the myocardium". Nat. Toxins Vol. 3 no. 5, pp.344-349.

18. Raonimalala A.F., Digaud A., (1980). Fournier P. Action of soluble carbohydrates from avocado (Persea gratissimaGaertner) fruit on utilization of calcium in the rat. Ann. Nutr. Ailment. Vol. 34 no. 4, pp.735-44.

19. Unlu, N.Z., Bohn, T, Clinton, S.K. and Schwartz, S.J. (2005). Carotenoid absorption from salad and salsa by humans is enhanced by the addition of avocado or avocado oil. J. Nutr. Vol. 135 no. 3, pp. 431-436.

20. Lopez Ledesma, R; FratiMunari, A C; Hernandez Dominguez, B C; Cervantes Montalvo, S., Hernandez Luna, M H : Juarez, C : Moran Lira, S. (1996). Monounsaturated fatty acid (avocado) rich diet for mild hypercholesterolemia. Arch-Med-Res. Vol. 27 no.4, pp.519-23.

21. Craigmill, A.L, Elide, R.N., Schultz, T.A., Hedrick, K. (1984). Toxicity of avocado (Persea americana var.) leaves: re-view and preliminary report. Vet. Hum. Toxicol., Vol. 26, pp. 381-383.

22. D. S. Amaza, A. D. Abue, N. Sambo, Nathan Dibal, A. D. T. Goji, A. J. Aniah and N. Victoria (2016). Effect of Aqueous Extract of Persea Americana on the Histology of the Liver of Albino Rat. IOSR Journal of Dental and Medical Sciences, 15 (6): 10-15. 